\title{
FUTSAL PARA PESSOAS COM DEFICIÊNCIA INTELECTUAL: desafios e possibilidades ${ }^{1}$
}

\section{FUTSAL FOR PEOPLE WITH INTELLECTUAL DISABILITIES: challenges and possibilities}

\section{FUTSAL PARA PERSONAS CON DISCAPACIDAD INTELECTUAL: retos y posibilidades}

(iD) Érica Roberta Joaquim

Escola de Educação Física e Esporte da Universidade de São Paulo (EEFE-USP), São

Paulo/SP, Brasil.

ericajoq@usp.br

iD Luiz Eduardo Pinto Basto Tourinho Dantas

Escola de Educação Física e Esporte da Universidade de São Paulo (EEFE-USP), São Paulo/SP, Brasil

Idantas@usp.br

iD Otavio Luís Piva da Cunha Furtado

Escola de Educação Física e Esporte da Universidade de São Paulo (EEFE-USP), São Paulo/SP, Brasil

otaviofurtado@usp.br

Resumo: O objetivo deste estudo foi analisar os desafios e possibilidades que emergiram na implementação de um programa de futsal para adultos com deficiência intelectual (DI). Pautado em uma representação de jogo (árvore de decisão) e nas perspectivas táticas de ensino, o programa foi permeado de obstáculos e desafios acerca das estratégias utilizadas para favorecer a compreensão de conceitos, heurísticas e ações de jogo (presentes na árvore de decisão e trabalhados a partir de jogos reduzidos e do jogo formal), exigindo adequações metodológicas no decorrer do programa, que vieram a contribuir com o desenvolvimento dos alunos no contexto do jogo.

Palavras-chave: Deficiência intelectual. Teoria do jogo. Educação física. Autonomia.

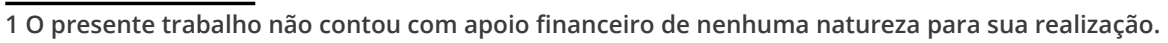


Abstract: The aim of this study was to analyze the challenges and possibilities that emerged in the implementation of a futsal program for adults with intellectual disabilities (ID). Based on a game representation (decision tree) and teaching tactical perspectives, the program was permeated with obstacles and challenges related to the teaching strategies used to contribute to the understanding of the concepts, heuristics and actions of the game (present in the decision tree and worked on from reduced games and formal games) requiring methodological adjustments throughout the program, which came to contribute to the development of students in the context of the game.

Keywords: Intellectual disability. Game theory. Physical education. Autonomy.

Resumen: El objetivo de este estudio fue analizar los desafíos y posibilidades que surgieron en la implementación de un programa de fútbol sala para adultos con discapacidad intelectual (DI). Basado en una representación del juego (árbol de decisiones) y la enseñanza de perspectivas tácticas, el programa estuvo impregnado de obstáculos y desafíos en cuanto a las estrategias utilizadas para favorecer la comprensión de conceptos, heurísticas y acciones del juego (presentes en el árbol de decisiones y trabajadas desde juegos reducidos y juegos formales) requiriendo ajustes metodológicos a lo largo del programa, que llegaron a contribuir al desarrollo de los estudiantes en el contexto del juego.

Palabras clave: Discapacidad intelectual. Teoría del juego. Educación física. Autonomía.

Submetido em: 14-10-2020

Aceito em: 10-06-2021 
FUTSAL PARA PESSOAS COM DEFICIÊNCIA INTELECTUAL: desafios e possibilidades

Érica Roberta Joaquim • Luiz Eduardo Pinto Basto Tourinho Dantas • Otavio Luís Piva da Cunha Furtado

\section{Introdução}

A deficiência intelectual (DI) é uma condição caracterizada pelo desenvolvimento cognitivo abaixo do esperado para a idade cronológica e dificuldades com o comportamento adaptativo que se manifestam antes dos 18 anos (SCHALOCK et al., 2010). A etiologia da DI é diversificada e pode resultar de diversos processos patológicos que interferem no funcionamento do sistema nervoso central (VASCONCELOS, 2004) e no desempenho funcional, exigindo adaptações para que essas pessoas possam lidar com as demandas físicas, motoras, cognitivas e sociais presentes na vida diária.

Nas últimas décadas, as mudanças na concepção de deficiência influenciaram a forma como a sociedade percebe e se relaciona com essas pessoas. Com o paradigma da inclusão, a sociedade passa a ser concebida como principal responsável por oferecer suporte à pessoa com deficiência, para que esta exerça seu papel de cidadão. Ainda hoje, vivemos o processo de apropriação e incorporação dos princípios que compõem esse paradigma, que consequentemente influenciam os programas de intervenções, para pessoas com alguma deficiência. No que tange às pessoas com $\mathrm{DI}$, um dos aspectos que se destacaram nas intervenções a partir desse novo cenário, iniciado na década de 1990 no Brasil, são as questões relativas à funcionalidade e a interação dessas pessoas com o ambiente físico e social, ressaltando como princípio orientador a promoção da autonomia (MANTOAN, 1998).

Segundo o Dicionário Houaiss (2009), autonomia é definida como: capacidade de governar-se pelos próprios meios; direito de um indivíduo tomar decisões livremente; independência moral ou intelectual. No contexto das intervenções para pessoas com DI, a autonomia demanda possibilidade de escolhas e agência sobre as próprias ações (BISSOTO, 2014; HARRIS, 2003; MANTOAN, 1998). Agência, como está sendo empregada neste estudo, refere-se à tomada de consciência do contexto em que a pessoa está inserida, suas possibilidades, responsabilidades e ações enquanto sujeitos transformadores (FREIRE, 1987). 
FUTSAL PARA PESSOAS COM DEFICIÊNCIA INTELECTUAL: desafios e possibilidades Érica Roberta Joaquim • Luiz Eduardo Pinto Basto Tourinho Dantas • Otavio Luís Piva da Cunha Furtado

Estimular a autonomia implica mobilizar o indivíduo a pensar por si mesmo, descobrir e criar os seus objetivos. Os programas de intervenção para pessoas com DI devem garantir uma ambiência pedagógica onde a curiosidade e a concentração sejam sempre bem-vindas como atitudes necessárias ao exercício de solução do problema.

Para Mantoan (1998, p. 97) "Se os conflitos são evitados, como poderão chegar a uma tomada de consciência sobre os problemas a resolver e como poderão ter a experiência de enfrentá-los?"

No entanto, para garantir que o exercício da autonomia seja formativo, no sentido que as pessoas com DI aprendam a viver o desequilíbrio (MANTOAN, 1998) quando expostas a situações adversas, é necessário cuidado, "uma atitude de ocupação, preocupação, de responsabilização e de envolvimento afetivo com o outro" (BOFF, 2014, p. 12).

As práticas corporais com sentido formativo, de lazer e saúde constituem um contexto importante para o desenvolvimento da autonomia dessa população e são utilizadas com frequência em programas de ensino. Entre os programas de intervenções motoras que demonstram impacto positivo no desenvolvimento dessas pessoas, os Jogos Esportivos Coletivos (JECS) apresentam-se como uma opção devido ao seu forte apelo social e potencial para atender alguns requisitos preconizados para promover o desenvolvimento: a prática de exercícios físicos e, como aponta Sherill (1986), um contexto de interação com outras pessoas que contribui para a construção de uma biografia e identidade individual e social.

Os JECs são caracterizados como um confronto entre duas equipes que se dispõem por um terreno de jogo, alternando situações de ataque e defesa, com o objetivo de marcar mais pontos e vencer o jogo. Os JECs também proporcionam uma atividade social estruturada, na qual os jogadores, divididos em duas equipes, estabelecem relações de cooperação e oposição entre si (TEODORESCU, 1984). 
FUTSAL PARA PESSOAS COM DEFICIÊNCIA INTELECTUAL: desafios e possibilidades

Érica Roberta Joaquim • Luiz Eduardo Pinto Basto Tourinho Dantas • Otavio Luís Piva da Cunha Furtado

Uma partida de JEC pode ser representada como um sistema dinâmico formado pelos jogadores e suas relações intra-equipe (cooperação) e inter-equipe (oposição), orientadas pelas múltiplas referências do jogo (regras, estratégias, modelo de jogo, concepção individual de jogo etc.). A evolução desse tipo de sistema é caracterizada por uma sucessão de eventos não lineares de difícil previsão. Essa característica faz com que o domínio das técnicas motoras da modalidade não garanta um desempenho bemsucedido, visto as exigências de permanentes adaptações frente às situações que emergem sob forte pressão temporal (SILVA; GRECO, 2009) participantes do Campeonato Metropolitano de Belo Horizonte, relacionando os mesmos com o desenvolvimento do conhecimento tático processual divergente (criatividade).

O futsal, o basquete, o handebol, o futebol, entre outros, são denominados JECs de invasão. Esse tipo de JEC é caracterizado pela participação simultânea de duas equipes em um terreno comum. Como resultado, o desafio de cada jogador é cooperar com seus companheiros de equipe e opor-se aos adversários, simultaneamente, em situações de ataque ou defesa (NOVAES; RIGON; DANTAS, 2014).

Devido às demandas dos JECs de invasão, Gréhaigne e Guillon (1992) apontam que estimular o jogador a perceber regularidades do jogo que auxiliem na compreensão de sua estrutura pode contribuir para a identificação e solução dos problemas de jogo e melhorar o desempenho do jogador. A identificação e a categorização desses problemas são possíveis pois o desenvolvimento do jogo é regido pelas restrições de cooperação (nas equipes) e oposição (entre as equipes), subordinadas à finalidade (ganhar) e às regras do jogo. Isso faz com que certos problemas se repitam, possibilitando categorizá-los em classes e investigar as referências (estratégias) que podem ser usadas para superá-los.

A aquisição desses conhecimentos acerca do jogo simplifica o relacionamento entre os jogadores e como eles percebem as situações (classes de problemas) que emergem da partida, como: o que devo fazer quando minha equipe está com a posse da bola 
FUTSAL PARA PESSOAS COM DEFICIÊNCIA INTELECTUAL: desafios e possibilidades Érica Roberta Joaquim • Luiz Eduardo Pinto Basto Tourinho Dantas • Otavio Luís Piva da Cunha Furtado

em situação de ataque? E, consequentemente, das classes de soluções, como me deslocar conduzindo a bola ou me desmarcar e oferecer linha de passe? Com isso, a demanda cognitiva do jogador tende a diminuir, liberando sua atenção para outros aspectos do desempenho (GARGANTA; PINTO, 1998).

Considerando as exigências dos JECs de invasão e as características de pessoas com DI, compreende-se como necessário ao processo de ensino/aprendizagem a articulação das particularidades do jogo e da população. De acordo com Joaquim e Dantas (2016) centrado nas perspectivas táticas de ensino de JEC (JEC, a prática de JECs de invasão sem adequações necessárias às pessoas com DI não incide em impacto positivo sobre o desenvolvimento dessas pessoas. Em razão disso, os autores propuseram uma representação de jogo que contém classes de problemas que emergiram do contexto de intervenção em adultos com DI e suas heurísticas ${ }^{2}$. Esse modelo de jogo foi utilizado em um programa de intervenção para pessoas com $\mathrm{DI}$, gerando aumento no número de ações que contribuem para a prática da modalidade, indicando que é possível aprimorar as ações de jogo em função dos critérios de causa e efeito estimulados nos JECs de invasão.

$\mathrm{Na}$ literatura relacionada à prática do futsal por pessoas com DI, são raros os estudos que abordem os aspectos práticos (relevantes para a capacitação profissional) sobre a implementação de um programa esportivo para tal população, com foco na autonomia e agência do participante, considerando uma perspectiva de ensino tática. Nesse sentido, o presente trabalho tem como objetivo descrever a trajetória pedagógica da implementação de um programa de futsal para adultos com DI, pautado nas perspectivas táticas de ensino. Adicionalmente, propomos problematizar alguns obstáculos e possíveis facilitadores para implementação de programas de intervenção dessa natureza, recorrendo aos relatos das aulas descritos em um diário de campo ao longo do programa.

2 "Um procedimento simples que ajuda a encontrar respostas adequadas, ainda que geralmente imperfeitas, para perguntas difíceis" (KAHNEMAN, 2012, p. 110). 


\section{Contextualização do programa e seus resultados}

Em 2016, Joaquim e Dantas (2016) publicaram os dados de um estudo sobre os efeitos de um programa de ensino de Futsal para adultos com DI, centrado nas abordagens táticas de ensino como propõem os autores Bayer (1979), Bunker e Thorpe (1982), Greco (2007), Mahlo (1970).

Participaram desse estudo 11 alunos com DI, com idade entre 18 e 40 anos. O programa de ensino foi constituído por 30 sessões de intervenção, com duração de $1 \mathrm{~h} 20 \mathrm{~min}$ cada, realizadas duas vezes por semana. $\mathrm{O}$ desenvolvimento do programa se deu com base em uma representação elaborada especificamente para as pessoas que participaram desse estudo, após observações de jogos formais do grupo e um período de convivência de aproximadamente 8 meses entre os pesquisadores e participantes, permitindo que fosse considerado o nível de desempenho e compreensão dessas pessoas acerca do futsal.

O modelo de jogo, denominado de árvore de decisão, foi construído formalizando as heurísticas mais genéricas para as classes de problemas e suas possíveis soluções de ações de jogo simplificadas, considerando o futsal e as características dos participantes da intervenção (JOAQUIM; DANTAS, 2016) centrado nas perspectivas táticas de ensino de JEC JEC. Esse instrumento foi elaborado com a finalidade de auxiliar na sistematização das atividades de ensino (jogos reduzidos ${ }^{3}$ ). Considera-se aqui que a equipe com a posse da bola estabelece ações de ataque, enquanto a equipe sem a posse da bola procura organizar-se defensivamente.

\section{Árvore de decisão}

\footnotetext{
3 Formas de jogos adaptados ou reduzidos são unidades funcionais do jogo formal. O jogo é configurado/modificado de acordo com os objetivos selecionados e sobre a ênfase proposta, mantendo e respeitando o que é essencial no jogo: cooperação, oposição e finalização (REVERDITO; SCAGLIA, 2007, p. 60).
} 
Figura 1: Esquema representativo do jogo

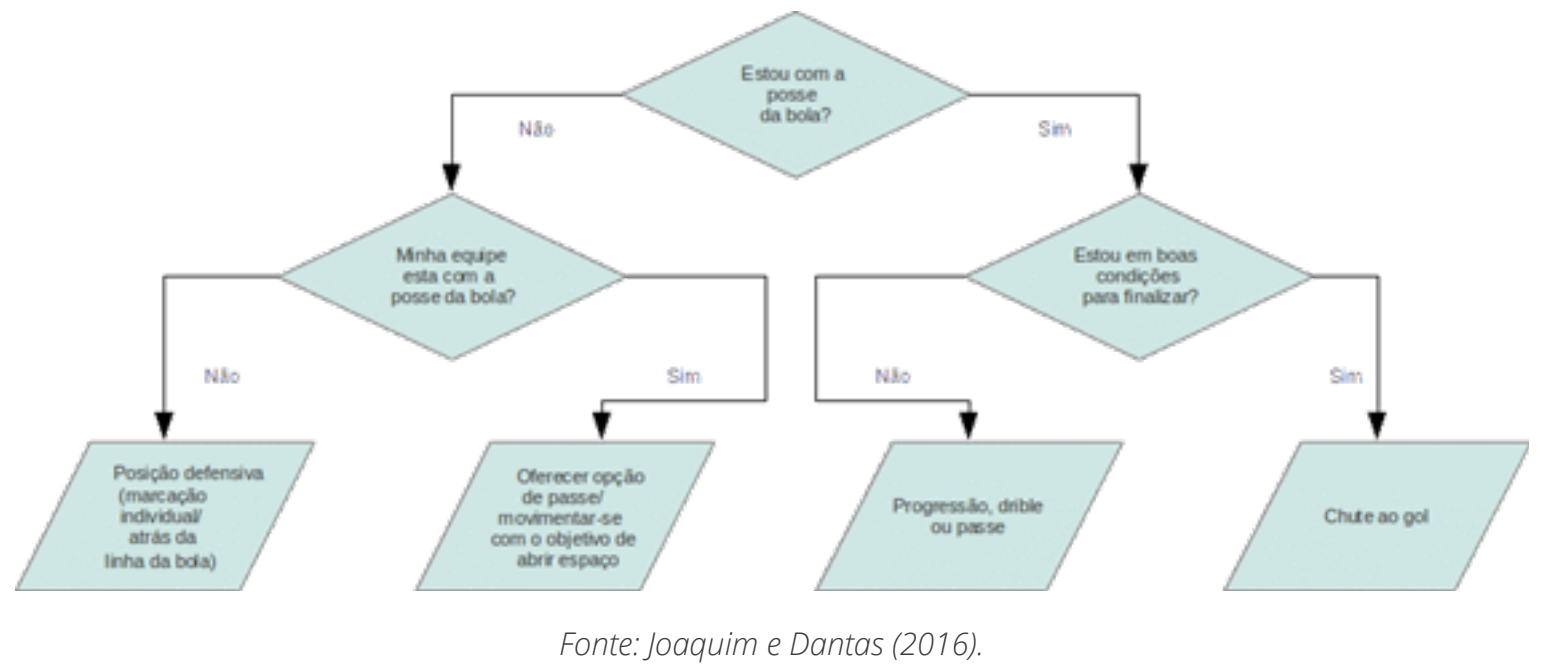

Para análise do estudo, os autores consideraram o número de ações de jogo realizadas durante uma partida. Cada jogador foi avaliado individualmente através da filmagem de uma partida de futsal com 8 minutos de duração, antes e após o programa. As ações de jogo observadas foram: progressão e/ou drible, passe, finalização, opção de passe, marcação atrás da bola, marcação individual, marcação atrasada - consideradas ações positivas - e finalização rifada, passe rifado, não atacar e não marcar - consideradas ações negativas. A classificação das ações em positivas e negativas são válidas apenas para o estudo apresentado, uma vez que considera o desempenho específico dos participantes, com base em observações de campo antes do início do estudo.

Como resultado, foi possível identificar que 9 alunos apresentaram aumento no número de ações positivas ao término do programa. Considerando a soma das ações do grupo, a frequência das ações de jogo positivas aumentou de 262 para 347 após o programa, já as ações de jogo negativas apresentaram uma pequena alteração de 63 para 58. As ações de "não atacar" e "não marcar" foram as que sofreram maior redução ao término do programa, enquanto as ações de "finalização rifada" e "passe rifado" aumentaram na avaliação final. Apesar de não estarem caracterizadas como ações positivas, o aumento das ações de "passe rifado" e 
FUTSAL PARA PESSOAS COM DEFICIÊNCIA INTELECTUAL: desafios e possibilidades Érica Roberta Joaquim • Luiz Eduardo Pinto Basto Tourinho Dantas • Otavio Luís Piva da Cunha Furtado

"finalização rifada" sugerem aumento de envolvimento dos alunos com o jogo (de uma forma não esperada), uma vez que uma das características iniciais do grupo foi permanecer parado em quadra sem realizar ações de jogo (JOAQUIM; DANTAS, 2016) centrado nas perspectivas táticas de ensino de jogos esportivos e coletivos (JEC.

Esses resultados, considerados pelos autores como "animadores", nos levaram a descrever com profundidade a trajetória dessa intervenção, agora sob uma perspectiva mais qualitativa. Para os autores deste estudo, a descrição e reflexão acerca dos acontecimentos possibilitará maior compreensão do fenômeno estudado, das possibilidades desse tipo de JEC para pessoas com DI, dos obstáculos e das alternativas utilizadas para superá-los no decorrer do desenvolvimento do programa.

\section{Metodologia}

A presente pesquisa caracteriza-se como um estudo de caso descritivo, no qual procurou-se pormenorizar a trajetória de um programa de futsal para adultos com DI. Para Yin (2001), o estudo de caso é considerado a estratégia mais adequada quando o pesquisador tem pouco controle sobre eventos em contexto da vida real e busca compreender comportamentos individuais e de pequenos grupos.

O programa foi desenvolvido no Centro de Práticas Esportivas da USP (CEPEUSP), por um período de 4 meses, totalizando 30 sessões de intervenções, com duração de $1 \mathrm{~h} 20$ minutos cada. Participaram 11 adultos com DI, com idade entre 18 e 40 anos, autorizados por seus pais e/ou responsáveis que assinaram um termo de consentimento livre e esclarecido (TCLE) referente ao presente estudo, aprovado pelo Comitê de Ética para pesquisas com seres humanos da Universidade de São Paulo.

A técnica de investigação utilizada foi a observação participante, com interações entre os integrantes do estudo e o pesquisa- 
FUTSAL PARA PESSOAS COM DEFICIÊNCIA INTELECTUAL: desafios e possibilidades Érica Roberta Joaquim • Luiz Eduardo Pinto Basto Tourinho Dantas • Otavio Luís Piva da Cunha Furtado

dor em situações formais e informais estabelecendo um constante diálogo (BOGDAN; TAYLOR, 1975). O instrumento para coleta de dados foi o diário de campo, realizado sistematicamente aula a aula com a seguinte estrutura:

Quadro 1: Estrutura do diário de campo

\begin{tabular}{|l|l|l|}
\hline AULA 1 & DESCRIÇÃO & $\begin{array}{l}\text { RELATOS } \\
\text { Sobre o Futsal: aspectos técnicos e estra- } \\
\text { tégicos táticos, desempenho dos alunos } \\
\text { Sobre o ambiente: perturbações e balizas } \\
\text { Sobre as relações sociais: com os colegas } \\
\text { e professora }\end{array}$ \\
\hline Objetivo & & \\
\hline Aquecimento & & \\
\hline Jogos Reduzidos & & \\
\hline Jogo Formal & & \\
\hline $\begin{array}{l}\text { Impressões, Conversas, Aconte- } \\
\text { cimento Geral: conversas com os } \\
\text { alunos, pais e/ou responsáveis so- } \\
\text { bre acontecimentos cotidianos ou } \\
\text { que antecederam a aula. }\end{array}$ & & \\
\hline
\end{tabular}

Fonte: Joaquim (2013).

Os dados coletados foram apresentados, interpretados e discutidos com base em autores como Ferretti (1999), Harris (2003), Rich (2004), Sherill (1986), Stainback e Stainback (1999), Linhares (1996), Vygotsky (1994), Gorla, Araújo e Carminato (2004), Hernández et al. (1998), Kirk et al. (2015) e Schalock et al. (2010), que tratam da deficiência intelectual no âmbito de processos de ensino aprendizagem, bem como estratégias de ensino em educação física.

\section{Reflexão na ação}

Inicialmente acreditamos que seja importante expor as motivações para a realização do Programa de ensino de Futsal para adultos com DI, que resultou na proposta pedagógica apresentada, e assim refletir sobre a trajetória dos alunos no programa. 
FUTSAL PARA PESSOAS COM DEFICIÊNCIA INTELECTUAL: desafios e possibilidades

Érica Roberta Joaquim • Luiz Eduardo Pinto Basto Tourinho Dantas • Otavio Luís Piva da Cunha Furtado

Antes da formalização do programa de futsal, os participantes do estudo praticavam o futebol de campo. Apesar de constituir-se como uma equipe de futebol, eventualmente o grupo era convidado a participar de festivais de futsal. No decorrer desses eventos, pudemos observar que, em muitas equipes, os alunos eram demasiadamente orientados por seus professores durante a partida sobre quais ações de jogo deveriam desempenhar e quando deveriam realizar. Em outras palavras, as decisões dos jogadores sobre suas próprias ações de jogo não pareciam emergir do seu conhecimento sobre o fenômeno, mas sim das vozes de seus professores, que na ânsia pela execução de ações que julgavam adequadas às demandas do jogo "narravam" as ações que deveriam ser desempenhadas. Aos alunos, por sua vez, cabia executar os comandos. Esta estratégia por comandos, centrada no professor/ técnico (RICH, 2004), atribui aos jogadores com DI papel secundário na tomada de decisões, implicando a limitação de sua autonomia no jogo.

Diante do interesse dos alunos no futsal, o programa de intervenção que inicialmente propunha-se a ensinar o futebol de campo passou a ser um programa de ensino de futsal para adultos com DI. Devido às exigências do fenômeno trabalhado e à mudança do ambiente físico do campo de futebol para a quadra de futsal, houve um aumento das demandas relativas à percepção espacial e temporal ${ }^{4}$ que desencadeou sucessivas ações de jogo inadequadas às situações. Uma ocorrência muito comum entre os jogadores no começo do programa de futsal era o início tardio da ação de jogo. Comumente, os jogadores posicionavam-se para receber a bola depois que o passe já havia acontecido, ou iniciavam uma corrida após o passe ser efetuado.

Para tentar minimizar essas dificuldades, uma das ações pedagógicas que utilizamos no início do programa, além das intervenções e explicações durante as atividades, foram as rodas de conversa ao término das aulas. Essas rodas de conversa eram realizadas com o intuito de reforçar os conceitos presentes na árvore

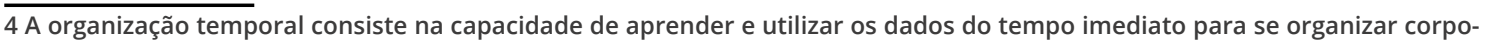
ralmente. Situar-se e adaptar-se no tempo em função das mudanças percebidas (ROSA NETO, 2002, p. 23). 
FUTSAL PARA PESSOAS COM DEFICIÊNCIA INTELECTUAL: desafios e possibilidades

Érica Roberta Joaquim • Luiz Eduardo Pinto Basto Tourinho Dantas • Otavio Luís Piva da Cunha Furtado

de decisão e estudados nos jogos reduzidos, e identificar se os alunos estavam apreendendo os conceitos e ações trabalhados em aula. No entanto, o envolvimento e participação desses alunos nas rodas de conversas foi incipiente. Como apresentam dificuldade com memória de trabalho (KIRK et al., 2015) e curtos períodos de atenção (FERRETTI, 1999; GORLA; ARAÚJO; CARMINATO, 2004; HERNÁNDEZ et al., 1998), os objetivos traçados para esse momento da aula não eram contemplados, uma vez que os alunos não participavam ou apenas repetiam a fala do professor.

Após algumas semanas, mudamos nossa proposta de roda de conversa no final da aula para pausas pontuais com conversas, explicações e questionamentos em busca da solução para os problemas enfrentados durante a prática motora. Utilizamos, então, a estratégia de descoberta guiada, proposta por Mosston e Ashworth (1986), mais centrada no aluno, situada nos problemas do jogo que trazíamos por meio dos jogos reduzidos. Um exemplo dessa estratégia pode ser ilustrado com a seguinte situação: o aluno com a posse da bola está sendo marcado por um oponente, enquanto seus companheiros de equipe se deslocam para o ataque sem perceber a possibilidade de que sua equipe perca a bola. Diante desse contexto, o jogo era pausado e perguntas realizadas: "o que pode acontecer se seu companheiro de equipe perder a bola?", "como você pode ajudá-lo?", "o que você pode fazer para receber a bola?", "você consegue receber a bola na posição em que se encontra?". Esses questionamentos auxiliaram no aprimoramento das ações de jogo e compreensão dos conceitos trabaIhados. Pudemos observar essa compreensão a partir do momento em que alguns alunos começaram a usar a expressão "dar linha de passe" durante o jogo.

Ainda nas primeiras semanas de sistematização do programa, pudemos identificar que o número de objetos ou objetivos, os quais os alunos deveriam ter como referência para suas tomadas de decisões nos jogos reduzidos, influenciavam o desempenho individual e coletivo. Quanto maior o número de regras ou subobjetivos nos jogos reduzidos (e.g., restrição do número de toques na bola 
FUTSAL PARA PESSOAS COM DEFICIÊNCIA INTELECTUAL: desafios e possibilidades

Érica Roberta Joaquim • Luiz Eduardo Pinto Basto Tourinho Dantas • Otavio Luís Piva da Cunha Furtado

ou a obrigatoriedade de passar o implemento quando atingir um determinado espaço da quadra), maior a dificuldade dos alunos com a leitura do jogo e tomada de decisão, resultando em ações inadequadas frente aos problemas do jogo. Particularmente, essa dificuldade acontecia quando havia maior número de jogadores na equipe. Um exemplo que se repetiu por algumas semanas foi que ao propor jogos com superioridade numérica, a equipe com mais jogadores não conseguia se beneficiar dessa situação, executando maior número de ações inadequadas às demandas, o que também acontecia nos jogos formais.

Schalock et al. (2010) aponta que pessoas com DI podem apresentar dificuldades com antecipação de acontecimentos e compreensão de relações de causa e efeito. Com o aumento de jogadores na equipe, a leitura e consequentemente a antecipação das ações de jogo tornava-se mais complexa, afetando a percepção da relação causa e efeito e a velocidade para desempenho das ações de jogo, que acontecem sob pressão temporal. Juntamente com a utilização da estratégia de descoberta guiada, nossa intervenção foi na direção de minimizar a complexidade das regras ao propor jogos com maior número de participantes ou jogos com superioridade numérica e aumentar a complexidade das regras quando o jogo reduzido era composto por número pequeno de jogadores $(1 \times 1,2 \times 2)$.

No decorrer do programa, pudemos observar que os alunos estavam compreendendo conceitos importantes presentes na árvore de decisão, como oferecer linha de passe - eles realizavam essa ação em diversas situações de jogo que exigiam compreensão do conceito. De acordo com Linhares (1996), a transferência da aprendizagem permite avaliar se o aluno compreendeu as estratégias para resolução de um problema, aplicando-a de maneira flexível em contextos novos e similares.

Com a aprendizagem dos conceitos acontecendo de maneira a contribuir com o desenvolvimento dos jogadores no futsal, iniciamos a proposta de trabalhar a movimentação dos alunos em quadra, uma vez que em diversos momentos os jogadores tendiam a 
FUTSAL PARA PESSOAS COM DEFICIÊNCIA INTELECTUAL: desafios e possibilidades Érica Roberta Joaquim • Luiz Eduardo Pinto Basto Tourinho Dantas • Otavio Luís Piva da Cunha Furtado

manter a organização dos espaços em quadra de maneira pouco eficiente, ou seja, muitos jogadores em um mesmo espaço, ocasionando confusões e disputas entre os jogadores de uma mesma equipe. Iniciamos propondo jogos reduzidos que utilizavam linhas traçadas no chão, formando quatro quadrantes em cada lado da quadra. A intenção desses jogos era estimular o equilíbrio das ocupações de espaço em quadra, no ataque e na defesa, e as marcações serviam como marcadores para reconhecer o equilíbrio espacial. As atividades nas quais utilizamos as demarcações dos quadrantes precisaram ser pausadas inúmeras vezes para explicação do objetivo e das estratégias de ocupação dos espaços, durante algumas aulas de forma mais insistente.

Após algumas sessões de treino os alunos começaram a faltar, sendo necessário telefonar para saber os motivos das ausências. Em uma dessas ligações, um aluno relatou o seguinte: "professora, eu não vou mais não, está muito difícil pra mim". A percepção de fracasso gerou muita frustração ao aluno, que manifestou o desejo de desistir do programa. Esse acontecimento levou-nos a refletir se realmente estávamos permitindo aos alunos a agência sobre a experiência de jogar futsal. Ponderamos que éramos nós, e não os participantes, que tínhamos como objetivo fazer o jogo ficar meIhor. Para os participantes, o futsal era uma atividade de lazer, mas a insistência dos pesquisadores em "ensinar" estava atrapalhando. O objeto de ensino é importante, porém não mais que as pessoas que fazem parte desse processo.

A partir desse acontecimento, percebemos que com nossas "boas intenções" estávamos indo contra o que adotamos como pressuposto desse programa de intervenção, isto é, garantir e desenvolver agência dos participantes sobre as suas vidas/sobre o jogo. Percebemos que estávamos colocando os nossos objetivos como pesquisadores como único significado para a experiência de jogar futsal, em detrimento dos significados que essas pessoas (participantes e responsáveis) traziam. Em outras palavras, deixamos de escutar os participantes (não respeitamos sua agência) até o momento em que eles gritaram: "professora, eu não vou mais 
FUTSAL PARA PESSOAS COM DEFICIÊNCIA INTELECTUAL: desafios e possibilidades

Érica Roberta Joaquim • Luiz Eduardo Pinto Basto Tourinho Dantas • Otavio Luís Piva da Cunha Furtado

não". Entre o início das atividades do programa e o começo das ausências (causadas pela frustração), foram aproximadamente 3 a 4 semanas. A partir de telefonemas, já com a consciência dos motivos pelos quais os alunos estavam faltando, modificamos a estratégia do programa e passamos a considerar cuidadosamente as restrições que propúnhamos para os jogos, tomando cuidado para que não fossem tão exageradas ao ponto de desmotivar o prazer pela atividade.

A partir desse momento, reestruturamos o programa na direção da intenção inicial: estimular a agência de nossos alunos, mantendo como base as perspectivas táticas de ensino, juntamente com a descoberta guiada. Passamos então a fazer uma escuta cuidadosa das falas dos alunos e responsáveis, e convidá-los para dizer quais jogos mais gostavam e como poderíamos modificá-los. De certa forma, nos permitimos abrir mão de um controle total das aulas, e passamos, acima de tudo, a considerar também os objetivos e anseios dos participantes que, aos poucos, retomaram as aulas do programa.

A preocupação com a agência dos jogadores, ressaltada pelo acontecimento descrito acima, quando inadvertidamente assumimos o significado da experiência do futsal sem ouvir os jogadores, passou a ser uma preocupação constante. Daí a nossa autovigilância em sempre fornecer um feedback (positivo) dirigido. A nossa maior dificuldade tem relação com o que nomeamos de cultura profissional de treinadores (e de pesquisadores exercendo esse papel). O fornecimento desse tipo de feedback, apesar das evidências favoráveis à sua utilização (HATTIE; TIMPERLEY, 2007), não parece ser muito comum no campo da Educação Física. Não encontramos trabalhos que tenham produzido dados sobre a frequência e tipo de feedback. No entanto, com base em nossa experiência empírica (e talvez dos leitores), na maioria das vezes nos deparamos com feedback negativo, e, quando positivo, não dirigido especificamente para o objeto de ensino, mas apelando para expressões genéricas, como: "muito bem", "boa", "Uhu", "isso" etc. A cultura de feedback positivo genérico também se 
FUTSAL PARA PESSOAS COM DEFICIÊNCIA INTELECTUAL: desafios e possibilidades

Érica Roberta Joaquim • Luiz Eduardo Pinto Basto Tourinho Dantas • Otavio Luís Piva da Cunha Furtado

fez presente e nos obrigou a um esforço sistemático para sua superação (talvez seja melhor chamar de elogio genérico) por uma cultura do feedback (positivo) dirigido ("parabéns, você ofereceu linha de passe").

Na trajetória do programa, os alunos com maiores dificuldades em se comunicar através da fala (se fazer entendido) apresentaram maior dificuldade em desempenhar as ações de jogo. Esses alunos apresentaram melhora na frequência de ações de jogo, mas ainda assim menores que a de seus companheiros com mais facilidade de comunicação verbal. Como não dominavam o ato da comunicação verbal, a elaboração de símbolos e significados atribuídos aos conceitos abstratos, apresentados de maneira verbal e gestual, podem não ter ajudado para a compreensão desses conceitos e ações em sua plenitude. Durante um longo período acreditou-se que pessoas com DI apenas conseguiam realizar atividades que envolvessem experiências concretas. No entanto, os constructos de Vygotsky (1994) afirmam que mesmo com dificuldades de comunicação essa população é capaz de abstrair e generalizar, elaborar conceitos e desenvolver processos psíquicos superiores (neste trabalho, tomar decisões). Estratégias para comunicação mais eficiente devem ser desenvolvidas para que os alunos com dificuldades de comunicação possam conseguir elaborar símbolos e significados. Stainback, S. e Stainback (1999) propõem sistemas de Comunicação Aumentativa Alternativa (CAA), que podem ser utilizados com alunos com dificuldade de fala e consistem em um conjunto de símbolos compartilhados que auxiliem na aprendizagem desses alunos.

Para além do desempenho dos alunos com dificuldades de comunicação verbal, havia um problema de comunicação entre os jogadores durante o jogo, o que tornava a tomada de decisão ainda mais difícil, principalmente para o jogador com a posse da bola, que tinha que resolver o problema de como prosseguir com o ataque ou sair de uma situação de pressão sem ajuda dos seus companheiros. Além disso, a falta de comunicação contribuía para a passividade dos jogadores que estavam sem a bola. No final, 
FUTSAL PARA PESSOAS COM DEFICIÊNCIA INTELECTUAL: desafios e possibilidades

Érica Roberta Joaquim • Luiz Eduardo Pinto Basto Tourinho Dantas • Otavio Luís Piva da Cunha Furtado

muitas vezes, o que tínhamos não era um JEC, mas uma atividade isolada. Para a qualidade de jogo que os alunos apresentavam, a comunicação corporal/gestual não era suficiente para que conseguissem comunicar as tomadas de decisões aos seus companheiros, de forma que as ações se articulassem umas às outras e contribuíssem com o desenvolvimento do jogo. Uma alternativa a essa situação foi apresentarmos o problema da falta de comunicação de forma situada, nos momentos de pausa e descoberta guiada (e.g., o que aconteceu para que perdesse a bola? O que você pode fazer para que seu companheiro de equipe perceba que precisa vir auxiliá-lo?). Aos poucos os alunos foram utilizando a comunicação verbal nos jogos, percebendo que isso favorecia seu time. Como consequência, conseguimos também com que os alunos mais passivos ficassem mais atentos ao jogo. Essa comunicação "entre iguais" (i.e., todos são alunos) favoreceu os alunos que tendiam a dispersar com estímulos externos, tornando-os mais agentes do jogo.

No decorrer das aulas os alunos foram aprimorando seus conhecimentos acerca da qualidade do desempenho de suas próprias ações de jogo, bem como das dos seus colegas. Isso fez emergir situações em que o jogador com a posse de bola, mesmo marcado pelo oponente, optasse pela ação de drible ou condução para não efetuar o passe a um companheiro de equipe em condição de receber a bola, mas com maiores dificuldades com as ações de jogo (por exemplo, controlar a bola). A discrepância entre o nível técnico dos jogadores gerava, de certa forma, a exclusão dos alunos com menor desempenho. Nesse sentido, os jogos reduzidos foram utilizados de forma que as modificações nas regras (número de toques na bola por jogador etc.), nas dimensões da quadra (a bola continua em jogo ao sair da quadra e encostar no alambrado/parede etc.) e nas ocupações dos espaços (ao atingir determinado espaço da quadra é necessário passar a bola etc.) possibilitassem que os alunos com menor desempenho fossem acionados em uma proporção similar aos demais jogadores. 
FUTSAL PARA PESSOAS COM DEFICIÊNCIA INTELECTUAL: desafios e possibilidades

Érica Roberta Joaquim • Luiz Eduardo Pinto Basto Tourinho Dantas • Otavio Luís Piva da Cunha Furtado

Outro ponto importante que segue na direção do problema que acabamos de apresentar é o cuidado com o equilíbrio das equipes nas disputas. É fundamental que haja um equilíbrio entre a quantidade de experiências de sucessos e fracassos no decorrer do programa. As experiências de sucesso são determinantes no desenvolvimento do senso de autoeficácia, mas o sucesso alcançado com dedicação e persistência, não aquele "doado", em que facilitamos em demasia a situação de aprendizagem. Tais experiências permitem que a pessoa estabeleça crenças positivas sobre sua capacidade de desempenhar ações que exerçam influência sobre eventos que o afetam (BANDURA, 1994). Isso exige dos professores envolvidos uma atenção muito grande e, junto com ela, uma capacidade de encontrar formas de reequilibrar o confronto continuamente.

\section{Considerações finais}

Partimos do pressuposto que os JECs de invasão pautados na árvore de decisão (i.e., ilustrada pelo futsal) constituem um contexto bastante oportuno para o ensino/aprendizagem de pessoas com DI. A partir do cenário apresentado podemos propor situações de jogo que contribuam para minimizar alguns problemas relativos à compreensão do jogo e favoreçam a aquisição de ações de jogo.

Ao permitir uma melhor compreensão do fenômeno, podemos auxiliar os participantes a expandir sua gama de ações de jogo, intensificando a participação e o envolvimento (i.e., motor, físico, cognitivo e social), permitindo o aprimoramento de habilidades e maior autonomia durante o jogo.

A elaboração de uma árvore de decisão com conceitos, heurísticas e ações apropriadas para resolver os problemas típicos do jogo dessa população foi essencial para o desenvolvimento do programa de ensino, uma vez que orientou a elaboração das 
FUTSAL PARA PESSOAS COM DEFICIÊNCIA INTELECTUAL: desafios e possibilidades Érica Roberta Joaquim • Luiz Eduardo Pinto Basto Tourinho Dantas • Otavio Luís Piva da Cunha Furtado

aulas e as ações pedagógicas do professor. Por outro lado, pode-se perceber nesse relato que isso não basta para o programa ser bem-sucedido. Uma variável fundamental é o professor, mais especificamente, um professor que através de uma autorreflexão contínua possa dar conta dos problemas inerentes a execução de qualquer programa de intervenção, no sentido de mantê-lo na direção almejada, isto é, a melhora da qualidade da experiência como jogador de futsal. Dessa forma, acreditamos que os alunos conseguiram se apropriar do fenômeno jogo de uma forma mais competente e autônoma, conhecendo suas possibilidades e potencialidades, otimizando sua participação em jogo, permitindo ao mesmo apoderar-se de um objeto cultural de maneira a usufruí-lo para desenvolver-se enquanto pessoa.

\section{Referências bibliográficas}

BANDURA, A. Self-efficacy. In: RAMACHAUDRAN, V. (ed.). Encyclopedia of human behavior. Nova York: Academic Press, 1994. p. 71-81.

BAYER, C. L`enseignement dês jeux sportifis collectis. Paris: Editora Vigot, 1979.

BISSOTO, M. L. Deficiência intelectual e processos de tomada de decisão: estamos enfrentando o desafio de educar para a autonomia? Educação Unisinos, São Paulo, v. 18, n. 1, p. 3-12, 2014. Disponível em: http://www.revistas.unisinos.br/index.php/educacao/article/view/edu.2014.181.01. Acesso em: 19 abr. 2021.

BOFF, L. Saber Cuidar. 20. ed. Petrópolis: Editora Vozes, 2014.

BOGDAN, R. C.; TAYLOR, S. J. Introduction to Qualitative

Research Methods. New York: John Wiley and Sons, 1975.

BUNKER, D.; THORPE, R. A model of teaching games for secondary school. Bulletin of Physical Education, Driffield, v. 18, n. 1, p. 5-18, 1982. 
FUTSAL PARA PESSOAS COM DEFICIÊNCIA INTELECTUAL: desafios e possibilidades

Érica Roberta Joaquim • Luiz Eduardo Pinto Basto Tourinho Dantas • Otavio Luís Piva da Cunha Furtado

FERRETTI, J. M. Breve guía diagnóstica y pronótica de los retrasos mentales. Revista Argentina de Clínica Neuropsiquiátrica, Buenos Aires, v. 8, n. 2, p. 157-173, 1999. Disponível em: http:// alcmeon.com.ar/8/30/Ferreti.htm. Acesso em: 19 abr. 2021.

FREIRE, P. Pedagogia do Oprimido. 17. ed. Rio de Janeiro: Paz e Terra, 1987.

GARGANTA, J; PINTO, J. O ensino do futebol. In: GRAÇA, A; OLIVEIRA, J. (ed.). O Ensino dos Jogos Desportivos. Porto: CEJD, FCDEF - Universidade do Porto, 1998. p. 95-136.

GORLA, J. I.; ARAÚJO, P. F. DE; CARMINATO, R. A. Desempenho psicomotor em portadores de deficiência mental: Avaliação e intervenção. Revista Brasileira de Ciências do Esporte, Campinas, v. 25, n. 3, p. 133-147, 2004.

GRECO, P. J. Iniciação Esportiva Universal: Metodologia de Iniciação Esportiva na Escola e no Clube. Belo Horizonte: Ed. UFMG, 2007. Disponível em: http://www.oldarchive.rbceonline. org.br/index.php/RBCE/article/view/244. Acesso em: 19 abr. 2021. GRÉHAIGNE, J. E; GUILLON, R. L'utilisation dês jeux d'opposition a 1'école. Revue de1'Education Physique, Paris, v. 32, n. 2, p. 51-67, 1992.

HARRIS, J. Time to make up your mind: Why choosing is difficult. British Journal of Learning Disabilities, Worcestershire, v. 31, n. 1, p. 3-8, 2003.

HATTIE, J.; TIMPERLEY, H. The power of feedback. Review of Educational Research, Thousand Oaks, v. 77, n. 1, p. 81-112, 2007. Disponível em: http://area.fc.ul.pt/en/artigos\%20publicados\%20internacionais/The\%20Power\%20of\%20Feedback_Hattie_ Timperley2007_77_1_81_112.pdf. Acesso em: 19 abr. 2021.

HERNÁNDEZ, M. R. et al. Actividad Física Adaptada: el juego y los alumnos com discapacidad. Barcelona: Paidotribo, 1998. AUTONOMIA In: Dicionário Houaiss Eletrônico, versão 3.0. Rio de Janeiro: Instituto Antônio Houaiss e Editora Objetiva LTDA, 2009. CD-ROM. 
FUTSAL PARA PESSOAS COM DEFICIÊNCIA INTELECTUAL: desafios e possibilidades Érica Roberta Joaquim • Luiz Eduardo Pinto Basto Tourinho Dantas • Otavio Luís Piva da Cunha Furtado

JOAQUIM, E. R. Ensino de futsal para pessoas com deficiência intelectual. 2013. 94 f. Dissertação (Mestrado em Ciência) Escola de Educação Física e Esporte, Universidade de São Paulo, São Paulo, 2013. Disponível em: https://www.teses.usp.br/teses/ disponiveis/39/39133/tde-26092013-073417/en.php. Acesso em: 19 abr. 2021.

JOAQUIM, É. R.; DANTAS, L. E. P. B. T. Ensino de Futsal para Pessoas com Deficiência Intelectual1. Revista Brasileira de Educação Especial, Marília, v. 22, n. 1, p. 93-110, 2016. Disponível em: https://www.scielo.br/scielo.php?pi$\mathrm{d}=$ =S1413-65382016000100093\&script=sci_arttext\&tlng=pt. Acesso em: 19 abr. 2021.

KAHNEMAN, D. Rápido e devagar: duas formas de pensar. Rio de Janeiro: Editora Objetiva, 2012.

$\mathrm{KIRK}, \mathrm{H}$. E. et al. Cognitive training as a resolution for early executive function difficulties in children with intellectual disabilities. Research in Developmental Disabilities, Durham, v. 38, s. n., p. 145-160, 2015. Disponível em: https://dro.dur. ac.uk/16317/1/16317.pdf. Acesso em: 19 abr. 2021.

LINHARES, M. B. M. Avaliação assistida em crianças com queixa de dificuldade de aprendizagem. Temas em Psicologia, Ribeirão Preto, v. 4, n. 1, p. 17-32, 1996. Disponível em: http:// pepsic.bvsalud.org/scielo.php?script=sci_arttext\&pid=S1413-389X1996000100003. Acesso em: 19 abr. 2021.

MAHLO, F. Acto Tático no Jogo. Lisboa: Compendium, 1970.

MANTOAN, M. T. E. Educação escolar de deficientes mentais: problemas para a pesquisa e o desenvolvimento. Cadernos CEDES, Campinas, v. 46, n. 19, p. 93-107, 1998. Disponível em: https://www.scielo.br/scielo.php?pi$\mathrm{d}=$ =0101-32621998000300009\&script=sci_arttext. Acesso em: 19 abr. 2021.

MOSSTON, M.; ASHWORTH, S. Teaching physical education. Ohio: Merryl Publishing Company, 1986. 
FUTSAL PARA PESSOAS COM DEFICIÊNCIA INTELECTUAL: desafios e possibilidades

Érica Roberta Joaquim • Luiz Eduardo Pinto Basto Tourinho Dantas • Otavio Luís Piva da Cunha Furtado

NOVAES, R. B.; RIGON, T. A.; DANTAS, L. E. P. B. T. A model for the game of futsal and subsidies for teaching. Movimento, Porto Alegre, v. 20, n. 3, p. 1039-1060, 2014. Disponível em: https://www.researchgate.net/profile/Thiago-Rigon/publication/297518419_The_Futsal_model_and_teaching_subsidies/ links/5e7cf065a6fdcc139c08ba29/The-Futsal-model-and-teachingsubsidies.pdf. Acesso em: 19 abr. 2021.

REVERDITO, R. S.; SCAGLIA, A. J. A gestão do processo organizacional do jogo: uma proposta metodológica para o ensino dos jogos coletivos. Motriz, Rio Claro, v. 13, n. 1, p. 51-63, 2007. Disponível em: http://www.educadores.diaadia.pr.gov.br/arquivos/File/2010/ artigos_teses/EDUCACAO_FISICA/artigos/handebol2.pdf. Acesso em: 19 abr. 2021.

RICH, S. Estratégias de instrução na educação física adaptada. In: WINNICK, J. (ed.). Educação Física e Esportes Adaptados. Barueri: Ed. Manole, 2004. p. 85-104.

ROSA NETO, F. Manual da avaliação motora. Porto Alegre: Artmed Editora, 2002.

SCHALOCK, R. et al. Intellectual Disability - Definition, Classification ad Systems of supports. 11. ed. Washington DC: AAIDD, 2010.

SHERILL, C. Adapted physical education and recreation. 3. ed. Dubuque, IA: Brown, 1986.

SILVA, M. V.; GRECO, P. J. A influência dos métodos de ensino-aprendizagem-treinamento no desenvolvimento da inteligência e criatividade tática em atletas de futsal. Revista Brasileira de Educação Física e Esporte, São Paulo, v. 23, n. 3, p. 297-307, 2009. Disponível em: https://www.scielo.br/scielo.php?pi$\mathrm{d}=$ S1807-55092009000300010\&script=sci_arttext. Acesso em: 19 abr. 2021.

STAINBACK, S.; STAINBACK, W. Inclusão: um guia para educadores. Porto Alegre: Editora Artimed, 1999. 
FUTSAL PARA PESSOAS COM DEFICIÊNCIA INTELECTUAL: desafios e possibilidades

Érica Roberta Joaquim • Luiz Eduardo Pinto Basto Tourinho Dantas • Otavio Luís Piva da Cunha Furtado

TEODORESCU, L. Problemas de teoria e metodologia nos jogos desportivos. Lisboa: Livros Horizonte, 1984.

VASCONCELOS, M. M. Retardo mental. Jornal de Pediatria, Porto Alegre, v. 80, n. 2, p. 71-82, 2004. Disponível em: https://www. scielo.br/scielo.php?pid=S0021-75572004000300010\&script=sci_arttext\&tlng=pt. Acesso em: 19 abr. 2021. VYGOTISKY, L. A formação social da mente. 5. ed. São Paulo: Martins Fontes, 1994.

YIN, R. K. Estudo de caso: planejamento e métodos. 2. ed. Porto Alegre: Bookman, 2001.

\section{Publisher}

Universidade Federal de Goiás. Faculdade de Educação Física e Dança. Publicação no Portal de Periódicos UFG. As ideias expressadas neste artigo são de responsabilidade de seus autores, não representando, necessariamente, a opinião dos editores ou da universidade. 